\title{
Da Regulamentação à Promoção - o rural nos planos nacionais de turismo $(1985-2011)^{1}$
}

\author{
Maria João Carneiro², Diogo Soares da Silva ${ }^{3}$, \\ Vítor Brandão ${ }^{4}$ e Elisabete Figueiredo ${ }^{5}$
}

Resumo: Os Planos Nacionais de Turismo (PNT) constituem documentos importantes para uma melhor compreensão das representações e dos significados sociais do rural e do turismo rural em Portugal. O presente artigo, procurando debater estas questões, tem por base a análise de conteúdo detalhada dos PNT ao longo dos últimos 30 anos, designadamente, os PNT dos períodos de 1985-1988 e 1989-1992 e o Plano Estratégico Nacional do Turismo (PENT) dos períodos de 20072010 e 2011-2015. A análise de conteúdo efetuada teve como suporte uma grelha de análise exaustiva, contendo múltiplas categorias (e valores correspondentes) identificadas a partir da revisão da literatura nacional e internacional sobre o mundo rural, as suas representações e significados, assim como sobre o turismo rural e as políticas e estratégias implementadas no âmbito da União Europeia (UE) e aplicadas em Portugal. A escolha deste período temporal toma como referência a data do primeiro PNT (1985) e da entrada de Portugal na Comunidade Económica Europeia (CEE) (1986). Da análise de conteúdo, identificámos as principais definições, características e produtos de Turismo em Espaço Rural (TER) associadas a cada um dos PNT, permitindo agrupar um conjunto de imagens e representações do rural e do TER.

Palavras-chaves: Planos Nacionais de Turismo, representações do rural, rural, significados do rural, turismo rural.

1. Esta comunicação integra-se no âmbito do Projeto Rural Matters - significados do rural em Portugal: entre as representações sociais, os consumos e as estratégias de desenvolvimento (PTDC/ CS-GEO/117967/2010), que é financiado pela Fundação para a Ciência e Tecnologia (cofinanciado pelo COMPETE, QREN e FEDER).

2. Professora Auxiliar no Departamento de Economia, Gestão e Engenharia Industrial, investigadora do GOVCOPP (Unidade de Investigação em Governança, Competitividade e Políticas Públicas), Universidade de Aveiro. E-mail: mjcarneiro@ua.pt

3. Bolseiro de Investigação, Departamento de Ciências Sociais, Políticas e do Território, Universidade de Aveiro. E-mail: diogo.silva@ua.pt

4. Mestrando em Gestão e Planeamento em Turismo, Departamento de Economia, Gestão e Engenharia Industrial, Universidade de Aveiro. E-mail: vmbrandao@ua.pt

5. Socióloga, Professora Auxiliar no Departamento de Ciências Sociais, Políticas e do Território, investigadora do GOVCOPP (Unidade de Investigação em Governança, Competitividade e Políticas Públicas), Universidade de Aveiro. E-mail: elisa@ua.pt 
Abstract: National Tourism Plans (NTP) are important documents for a better understanding of representations and social meanings of rural and rural tourism in Portugal. This paper, aiming to discuss these issues, is based on the detailed content analysis of the NTP over the last 30 years, namely, the NTP for the periods 1985-1988 and 1989-1992 and the National Strategic Plan for Tourism for the periods of 2007-2010 and 2011-2015. The content analysis performed was supported by a comprehensive analysis grid containing multiple categories (and corresponding values) identified based on the review of national and international literature on the rural world, its representations and meanings, as well as on rural tourism and policies and strategies implemented in the European Union (EU) and implemented in Portugal. The choice of this time period has referred to the date of the first NTP (1985) and Portugal's entry in the European Economic Community (EEC) (1986). Based on the content analysis, we identified the main definitions, characteristics and products of Rural Tourism (RT) associated with each of the NTP, allowing to group a set of images and representations of rural and RT.

Key-words: National tourism plans, representations of the rural, rural, meanings of the rural, rural tourism.

Classificação JEL: L83, R50.

DOI: http://dx.doi.org/10.1590/1234-56781806-94790053s01001

\section{Introdução}

Em Portugal, em 2012 o turismo gerou 8606 milhões de euros de receitas (INE, 2013). Neste mesmo ano existiam já em Portugal 704 unidades de TER que receberam em 2012323 mil hóspedes (INE, 2013). No entanto, em Portugal, ao longo das últimas décadas têm-se verificado diversas alterações nas políticas e estratégias associadas ao TER, resultantes, provavelmente, dos diversos "olhares" e perspetivas que têm existido ao longo dos anos sobre o rural, as suas potencialidades para o turismo, e sobre o próprio TER.

Os Planos Nacionais de Turismo (PNT) constituem documentos importantes para uma melhor compreensão das representações e dos significados sociais sobre o rural ${ }^{6}$ e sobre o turismo rural em Portugal. O presente artigo, com base na análise de conteúdo, tem como principal objetivo compreender de uma forma mais aprofundada como o rural e a ruralidade são apresentados nos PNT, em Portugal, no período compreendido entre 1985 e 2011. A escolha deste período tempo-

6. No âmbito do projeto Rural Matters são também analisados outros discursos sobre o rural, designadamente os veiculados pelos programas específicos dirigidos ao desenvolvimento rural, pelos Programas dos Governos Constitucionais, pelos meios de comunicação social e pelo cinema, assim como pelas campanhas promocionais de turismo. ral toma como referência a data do primeiro PNT (1985) e da entrada de Portugal na CEE (1986).

Da análise de conteúdo, identificaram-se as principais definições, características e produtos de turismo rural associados a cada um dos PNT, permitindo agrupar um conjunto de imagens e representações do rural e do turismo rural. A evidência empírica produzida, essencialmente de natureza qualitativa, destaca a passagem de uma perspetiva centrada na regulamentação do turismo rural, relacionada com a preocupação com a defesa, proteção e valorização do património cultural e natural (PNT), para uma abordagem orientada para a especialização, diversificação e promoção do rural em geral e do turismo rural em particular (PENT), ou seja para a mercantilização do rural, muito associado à natureza.

O rural aparece frequentemente associado ao património natural e cultural, nomeadamente à agricultura, arquitetura típica, beleza paisagística e áreas protegidas. No que diz respeito aos produtos de turismo no espaço rural, o PNT centra-se no turismo rural, agro-turismo e turismo de habitação e o PENT, embora não utilizando a expressão turismo rural, centra-se sobretudo no touring cultural e paisagístico, no turismo de natureza, turismo de saúde/bem-estar, turismo gastronómico e enoturismo.

No presente artigo procede-se primeiramente a uma revisão de literatura que integra duas sec- 
ções, abordando-se na primeira secção o TER em Portugal e sendo a segunda secção dedicada aos PNT em Portugal. Posteriormente especifica-se a metodologia utilizada no estudo empírico do artigo, discutem-se os principais resultados do estudo e apresentam-se as principais conclusões.

\section{O turismo em espaço rural em Portugal - breve evolução}

O desenvolvimento do turismo em Portugal foi particularmente acentuado a partir do início da década de 60 do século passado e deveu-se ao fim da II Guerra Mundial, ao maior acesso a férias pagas, à generalização do uso do automóvel e ao desenvolvimento do transporte aéreo (CUNHA, 2013). Contudo havia ainda uma grande concentração da procura turística em determinados mercados, como o inglês, e o desenvolvimento do turismo estava ainda muito concentrado em determinadas regiões - Algarve, região de Lisboa e Madeira - cujos atrativos estão associados, essencialmente, ao turismo de sol e mar (CUNHA, 2013). A partir deste boom, o desenvolvimento do turismo em Portugal iniciou um longo percurso marcado pela aposta crescente na diversificação e qualidade da oferta.

O TER constitui, pelas suas características, um produto que pode assumir um papel crucial na diversificação da oferta turística e na atenuação de assimetrias regionais. Na verdade, como referem Kastenholz et al. (1999), o desenvolvimento do TER resultou parcialmente da crescente procura, por parte dos visitantes, de autenticidade, contacto com a natureza e cultura, mas também do crescente reconhecimento do potencial turístico de outros recursos além do sol e praia. No âmbito do turismo, embora se reconheça que as áreas rurais poderão ter alguns constrangimentos, considera-se também que estes territórios possuem um conjunto diversificado de elementos atrativos para os visitantes, tais como a paisagem, os rios, a agricultura, os edifícios históricos, a arquitetura rural e os modos de vida tradicionais, podendo o turismo ter um importante papel na preservação e valorização das áreas rurais (GARROD et al., 2006). O TER é um produto através do qual os visitantes podem tomar contacto e usufruir de todos estes elementos, uma vez que o TER se caracteriza por ser um tipo de turismo localizado em áreas rurais, com funcionalidade rural (desenvolvido com base nas características particulares do mundo rural tais como o contacto com a natureza e pequenas empresas características do mundo rural), rural em termos de escala (com pequenas povoações e pouco espaço construído) e tradicional no seu carácter crescendo lentamente e organicamente (baseado em estruturas tradicionais e em património identitário da comunidade), podendo assumir diversas tipologias (LANE, 1994).

Apesar das suas potencialidades, de acordo com Silva e Carvalho (2011) é apenas a partir do final da década de 80, com a discussão que levou à elaboração do relatório da Comissão Europeia "O Futuro do Mundo Rural" (CCE, 1988), que a associação entre turismo e desenvolvimento rural adquire maior relevância, passando o TER a ser encarado como uma mais-valia para o desenvolvimento económico das regiões a partir da década de 90 (JENKINS et al., 1998). Para tal desenvolvimento, a iniciativa "Ano Europeu do Turismo" assumiu particular relevância (1990). Esta iniciativa, sendo a primeira na área do turismo a nível europeu, incluía orientações relacionadas com o turismo rural e originou a elaboração de um pacote de medidas comunitárias para o fomento do turismo rural, centrado na melhoria da oferta, valorização, promoção e comercialização do TER.

Em Portugal, o TER surge com alguma expressão, enquanto modalidade regulamentada, na década de 80 . O alojamento de TER surge, primeiramente, associado à recuperação de casas apalaçadas e ao seu aproveitamento para o turismo (PINA, 1988). Após as supracitadas orientações europeias do início da década de 90, Cavaco (1999) refere que a oferta de alojamentos turísticos em áreas rurais foi sendo paulatinamente consolidada graças ao aumento da procura e da diversidade de atividades desenvolvidas nestas áreas, para o qual contribuíram 
também, segundo Figueiredo (2003, p. 76), programas europeus como o LEADER, o RIME e o SAJE e programas nacionais como o Programa de Promoção do Potencial de Desenvolvimento Regional (PPDR) (1996-1999), no âmbito do qual foi executado o Programa das Aldeias Históricas, que possibilitou a atribuição de fundos a dez aldeias das Beiras para, entre outros investimentos, reconstruir edifícios, instalar infraestruturas e requalificar monumentos com vista à "viabilização de novas funções das áreas rurais, muito particularmente as associadas ao turismo, ao artesanato e ao comércio".

Silva e Carvalho (2011, p. 318) referem que o TER em Portugal "[...] beneficia desde meados dos anos 70 de apoios financeiros directos e, ao ser reconhecido como de utilidade pública, pôde aceder a financiamentos do Fundo de Turismo". Antes da adesão de Portugal à CEE, em 1986, o TER já beneficiava de ajudas financeiras. No entanto, é a partir dessa altura que é alvo de um forte impulso, fruto das ajudas económicas materializadas nos diversos Quadros Comunitários de Apoio - QCA I (1989-1993), II (1994-1999), III (2000-2006) e no atual QREN (2007-2013) (SILVA e CARVALHO, 2011).

Desde a década de 80, o conceito de alojamento de TER expresso na legislação portuguesa7 sofreu várias alterações, como resultado, parcialmente, de modificações na visão relativamente ao que deve ser o caráter identitário do TER e de necessidades decorrentes da viabilização económica desta modalidade de alojamento. Essas alterações estão relacionadas, entre outros aspetos, por exemplo, com a obrigatoriedade do proprietário da unidade de alojamento residir ou não na unidade, com o número de quartos e com as suas características arquitetónicas. Atualmente existem em Portugal várias modalidades de alojamento de TER que englobam, entre outras, unidades integradas em explorações agrícolas e

7. Por exemplo, Decreto-Lei no $251 / 1984$ de 25 de julho, Decreto-Lei no 54/2002 de 11 de março, Decreto Regulamentar no 13/2002 de 2 de março, Decreto-Lei no 39/2008 de 7 de março, Portaria no 937/2008 de 20 de agosto, Decreto-Lei no 228/2009 de 14 de setembro. hotéis rurais. Em 2012 existia já um total de 704 unidades de TER particularmente concentradas nas NUTS II Norte (onde se localizam cerca de metade das unidades de TER), Alentejo e Centro, o que contribui para atenuar um pouco os desequilíbrios regionais, nomeadamente os associados ao desenvolvimento turístico (INE, 2013).

\section{Os planos nacionais de turismo em Portugal}

Os PNT são documentos nos quais se pode identificar um conjunto de objetivos e estratégias governamentais para o desenvolvimento do setor do turismo em Portugal, nomeadamente no que concerne a produtos turísticos a dinamizar, regiões com potencial de desenvolvimento turístico (ordenamento turístico) a considerar, bem como mercados-alvo a atrair e que deverão ser objeto de ações de marketing.

Os PNT constituem, assim, documentos nos quais é possível observar representações, isto é, perspetivas, existentes sobre o rural e a ruralidade. No contexto destes planos, o rural e a ruralidade emergem como importantes elementos de produtos promovidos junto dos visitantes, o que pode contribuir, em grande medida, para a reconfiguração dos territórios rurais. Efetivamente, uma das formas atuais de (re) criação do rural é o aproveitamento turístico do espaço rural (BUTLER e HALL, 1998; PEIXOTO, 2002; PÉREZ, 2003; FIGUEIREDO, 2011; MATOS FERNANDES, 2013). Neste sentido, Covas (2011, p. 59) considera que o "espaço rural é, cada vez menos, um espaço produtor e, cada vez mais, um espaço produzido" e que "trabalhamos mais com representações do mundo rural, quase todas de proveniência e inspiração urbanas, do que com o mundo rural propriamente dito". Estas dinâmicas têm marcado o desenvolvimento de muitas áreas rurais nas últimas décadas.

Na década de 80 do século XX, verificavam-se em Portugal elevadas taxas de crescimento ao nível do turismo ao nível de entradas de turistas e de receitas, e que tiveram como consequência 
um desenvolvimento do turismo pouco planeado e não acompanhado da construção de infraestruturas adequadas, bem como a degradação de algumas áreas turísticas (CUNHA, 2013). Foi nesta década que foi criado o primeiro PNT em Portugal, o PNT de 1985-1988. Este plano constitui o primeiro plano estratégico para o turismo em Portugal, tendo sido criado num período em que a ênfase na qualidade turística passou a assumir grande relevância ao nível da agenda política dos responsáveis pelo turismo português (Pina, 1988). Essa preocupação foi sendo cada vez maior e foi acompanhada pelo aparecimento de diversos instrumentos de apoio ao investimento na área do turismo. O PNT defendia uma mudança de estratégia, no sentido de alargar regionalmente a oferta turística e de promover outros produtos diferentes dos clássicos sol e mar.

Alguns dos principais objetivos deste plano estavam relacionados com o ordenamento turístico do território e a redução dos desequilíbrios regionais, bem como com a preservação e valorização do património turístico (SECRETARIA DE ESTADO DO TURISMO, 1985). Foi também definido no PNT (1985-1988) um conjunto de áreas-chave, nomeadamente o termalismo, a animação, a estruturação administrativa, a formação profissional, os investimentos e a promoção turística (SECRETARIA DE ESTADO DO TURISMO, 1985). Para o período 1989-1992 foi elaborado um novo PNT que, no entanto, seguia as mesmas linhas orientadoras do seu antecessor. Durante mais de uma década, não foi concebido qualquer plano. É apenas em 2007 que o seu sucessor, o PENT, é elaborado, para o período 2007-2010 que foi já objeto de uma revisão (2011-2015).

O PENT preconiza a consolidação e desenvolvimento de 10 produtos turísticos estratégicos: Sol e Mar, Touring Cultural e Paisagístico, City Break, Turismo de Negócios, Turismo de Natureza, Turismo Náutico, Saúde e Bem-estar, Golfe, Resorts Integrados e Turismo Residencial, e Gastronomia e Vinhos (TURISMO DE PORTUGAL, 2007). Este plano identifica ainda as regiões em que deve haver uma forte aposta no desenvolvimento destes produtos. Segundo Cunha (2013), este plano tem o mérito de encorajar o desenvolvimento de novos destinos turísticos e o reforço do desenvolvimento de outros destinos. É interessante observar que, neste plano, a estratégia de aposta na qualidade (que implica, entre outros aspetos, formação, modernização empresarial e a melhoria da qualidade urbana, ambiental e paisagística) é também acompanhada por outras estratégias que se baseiam, entre outros aspetos, no aumento da acessibilidade aérea, na melhoria da promoção e distribuição e na aposta em eventos e criação de conteúdos distintivos e inovadores. Em 2011 são apresentadas algumas propostas para a revisão do plano para o horizonte de 2015 (TURISMO DE PORTUGAL, 2011), onde é reforçada a importância da sustentabilidade no desenvolvimento turístico.

\section{O rural nos planos nacionais de turismo (1985-2011)}

\subsection{Metodologia}

No âmbito do projeto Rural Matters foi efetuada uma análise de conteúdo a 84 documentos associados às políticas e instrumentos de apoio ao Turismo Rural em Portugal, relativos ao período entre 1985 e 2011, no qual estão incluídos os PNT. Como já referido, a escolha deste período teve como referência a adesão de Portugal na CEE e a entrada em vigor do primeiro PNT (1986). A análise de conteúdo efetuada aos documentos associados às Políticas e Instrumentos de Apoio ao Turismo Rural em Portugal teve como objetivo principal identificar as principais representações, imagens e símbolos relativos à ruralidade, aos territórios rurais e aos seus processos de desenvolvimento

A técnica de análise utilizada baseia-se no exame do conteúdo e de outros aspetos de documentos de texto, áudio, imagem ou vídeo, procurando descrevê-los de forma sistemática (e.g. ZHOU e DESANTIS, 2005). Para tal, tornou-se imperativo definir os principais conceitos, que se desdobraram em categorias e em valores concre- 
tos que se pretendiam identificar nos documentos. Esta relação é sintetizada em extensivas grelhas de análise e, posteriormente, transportada para o software NVivo (e.g. FIGUEIREDO e RASCHI, 2012, SOARES DA SILVA e FIGUEIREDO, 2013). Os principais conceitos (e atributos associados) identificados e operacionalizados, a partir de uma exaustiva revisão bibliográfica foram os seguintes: Rural, Ambiente, Ruralidade, Campo, Paisagem Rural, Turismo Rural e Desenvolvimento Rural. A análise envolveu a criação de uma base no software NVivo 10, na qual foram inseridos e classificados, segundo as suas características (tipo de documento, período e fonte), os documentos relativos ao turismo rural a examinar, assim como a criação de categorias de análise (nodes) às quais são associadas, após cuidada leitura, as noções veiculadas nos documentos, através da codificação ${ }^{8}$ de partes destes. Foi também efetuada a pesquisa das 300 palavras mais frequentes nos documentos, assim como pesquisas de palavras e expressões relativas ao rural e à ruralidade, consubstanciadas nos indicadores acima referidos, tendo sido extraídos destas análises vários outputs gráficos e textuais que ajudam a tornar evidentes as conclusões retiradas da análise dos documentos.

Este trabalho centra-se especificamente na análise de quatro documentos criados por entidades governamentais associadas ao turismo em Portugal: os dois PNT (relativos aos períodos 1985-1988 e 1989-1992) e o PENT (2007-2010) assim como a sua revisão (2011-2015). Importa referir, no entanto, que a análise dos PNT incidiu apenas sobre as partes do documento relativas ao espaço rural enquanto recurso para o desenvolvimento turístico e sobre o turismo suscetível de ser realizado em áreas rurais.

\subsection{Resultados e discussão}

Numa perspetiva geral, o rural no PNT (19851988) aparece essencialmente associado ao património natural e cultural, que constitui o principal

8. Por codificação, na análise de conteúdo, entende-se a associação de partes dos documentos a categorias de análise que, por sua vez, se associam a conceitos. elemento de atração turística das áreas rurais, fomentando fluxos de turistas e permitindo que cada localidade, como potencial destino, construa a sua orientação turística. A ênfase é colocada nos elementos naturais e culturais, como pode ser constatado no PNT (1985-1988):

“O património natural e cultural constituem, simultaneamente, a base essencial em que assenta o desenvolvimento do turismo e os principais factores de atracção turística" (PNT 1985-1988) (SECRETARIA DE ESTADO DO TURISMO, 1985, p. 16)

“Os estudos das motivações que estão na origem das deslocações turísticas têm demonstrado que não são os equipamentos desportivos e hoteleiros que originam estas deslocações mas sim, em primeiro lugar, os factores naturais e o património cultural" (PNT 1985-1988) (SECRETARIA DE ESTADO DO TURISMO, 1985, p. 16).

"Portugal oferece boas possibilidades de
desenvolvimento do turismo rural ou agrotu-
rismo que noutros países tem conhecido um
grande êxito. A presença de vastos interiores
ricos e atractivos naturais e paisagísticos, a
originalidade da vida rural desconhecidas dos
meios urbanos, a relação das pessoas com a
natureza, a arquitectura das aldeias, são ele-
mentos que, correctamente organizados cons-
tituem um grande potencial turístico" (PNT
1985-1988) (SECRETARIA DE ESTADO DO
TURISMO, 1985, p. 157).

Os recursos oferecidos pelas zonas rurais (nomeadamente a arquitetura tipicamente rural, o clima, as paisagens e modos de vida) possibilitam o desenvolvimento de diversas modalidades de turismo no espaço rural, tais como o turismo rural ou o agroturismo.

Em linha com uma visão multifuncional das áreas rurais, o TER é visto como um manancial de oportunidades para o desenvolvimento do interior do país. Segundo o PNT (1985-1988), o desenvolvimento turístico do interior deverá passar por uma aposta nas acessibilidades, no desenvolvimento do termalismo, do turismo 
Tabela 1. Número de ocorrências de palavras/expressões associadas ao rural e turismo rural nos PNT/PENT

\begin{tabular}{|c|c|c|c|c|c|c|}
\hline & $\begin{array}{c}\text { PNT } \\
(1985-1989)\end{array}$ & $\begin{array}{c}\text { PNT } \\
(1989-1993)\end{array}$ & $\begin{array}{l}\text { Total } \\
\text { PNTs }\end{array}$ & PENT & $\begin{array}{l}\text { Revisão } \\
\text { PENT }\end{array}$ & $\begin{array}{l}\text { Total PENT + } \\
\text { Revisão PENT }\end{array}$ \\
\hline Agroturismo/Agro-turismo & 1 & 2 & 3 & 0 & 0 & 0 \\
\hline Turismo rural/Turismo em espaço(s) rura(l/is) & 6 & 14 & 20 & 1 & 0 & 1 \\
\hline Hotéis rurais & 0 & 2 & 2 & 1 & 0 & 1 \\
\hline Turismo de natureza & 0 & 0 & 0 & 32 & 1 & 33 \\
\hline Paisagem & 5 & 3 & 8 & 29 & 2 & 31 \\
\hline Natureza & 3 & 7 & 10 & 48 & 1 & 49 \\
\hline Rural/rurais/ruralidade & 15 & 22 & 37 & 7 & 3 & 10 \\
\hline Áreas protegidas & 0 & 5 & 5 & 3 & 0 & 3 \\
\hline
\end{tabular}

Fonte: Elaboração própria.

cinegético e pesca desportiva, do TER nas suas diferentes modalidades ${ }^{9}$, no património cultural e ambiental, no campismo e caravanismo, e nos grandes parques e reservas naturais. No que diz respeito ao turismo rural, o PNT procura fomentar esta modalidade de turismo através da instalação de pequenas unidades de alojamento, aproveitando explorações agrícolas, recuperando montes alentejanos, investindo em informação e formação, inventariando propriedades e habitações, apostando também na criação de apoios financeiros. Para concretizar estes apoios, o PNT contemplava o recurso ao Fundo Europeu de Orientação e Garantia Agrícola (FEOGA), sendo o financiamento concedido através do Instituto de Financiamento da Agricultura e Pescas (IFAP).

Quanto ao rural que aparece no PNT (19891992), a ênfase continua a ser nos recursos locais, que devem ser aproveitados para a prática do TER. Este tipo de turismo permite que os turistas usufruam de paisagens exuberantes, modos de vida rural e da hospitalidade dos residentes. Este PNT coloca novamente a ênfase num conjunto de fatores como as acessibilidades, o termalismo, o turismo cinegético, a pesca desportiva, o TER, o património cultural e ambiental, o campismo e o caravanismo e os parques naturais e reservas, que conferem valor acrescentado ao desenvolvimento turístico. Neste plano é dada particular importância às áreas protegidas, alvo de procura crescente por parte dos turistas, cuja principal motivação

9. Modalidades que, na altura, correspondiam ao turismo de habitação, turismo rural, agroturismo e hotéis rurais. é o contacto com a natureza. Igual relevância é conferida ao TER, nas suas diferentes modalidades, dado o seu contributo para a proteção e valorização do património natural e cultural. No âmbito do TER, confere-se ênfase à reclassificação das unidades de alojamento existentes, sendo a tendência para um crescente interesse quanto aos novos tipos de turismo existentes no espaço rural. As regiões menos desenvolvidas do interior do país passaram a ser o alvo prioritário de novas iniciativas de TER.

No PENT (2007-2010) são enumerados diversos recursos com capacidade de atração turística, alguns deles intimamente ligados aos espaços rurais, como é o caso da ruralidade, da planície e da floresta. Apesar disto, verifica-se que no documento relativo ao PENT só há uma referência ao turismo no espaço rural, havendo muito mais referências ao produto turismo de natureza, que também pode ser desenvolvido em áreas rurais. Assim, o TER não se encontra entre os produtos estratégicos identificados no plano, ao contrário do turismo de natureza, o que revela o elevado valor que é conferido a este último produto, especificamente para as regiões da Madeira, Açores, Centro e Porto e Norte de Portugal. O documento da revisão do PENT para o período compreendido entre 2011 e 2015 reforça a importância do turismo na economia portuguesa, embora se esbatam as referências feitas ao rural e ao turismo de natureza.

Tendo em atenção as representações do rural nos planos acima mencionados, a Tabela 1 sintetiza as ocorrências de cada palavra/expres- 
são relativa ao rural nos quatro documentos, de modo a ilustrar as diferenças na forma como o turismo rural é abordado nos planos.

Da análise da frequência destas palavras, reforça-se o facto de as referências ao TER serem praticamente inexistentes nos PENT, havendo apenas uma referência à expressão "turismo em espaço rural" na secção dedicada ao turismo na região do Alentejo e associada ao papel do turismo para o desenvolvimento de áreas rurais:

“O desenvolvimento de produtos em zonas rurais será implementado tendo em conta a estratégia nacional para o desenvolvimento rural, nomeadamente quanto ao turismo em espaço rural" (PENT) (TURISMO DE PORTUGAL, 2007, p. 82)

Em contraste, as expressões "turismo rural" ou "turismo em espaço(s) rura(l/is)" encontram-se vinte vezes no conjunto de ambos os PNT, seis no documento relativo ao período 1985-1989 e catorze no documento posterior. A principal justificação para tal discrepância pode ser explicada pela elevada quantidade de referências ao "turismo de natureza" no PENT, sugerindo uma transição de uma abordagem ao turismo rural nas suas diversas vertentes para um turismo essencialmente ligado à natureza e à paisagem. $\mathrm{O}$ turismo de natureza surge no PENT como um dos dez produtos turís- ticos estratégicos e a quantidade de referências à expressão "turismo de natureza" nos quatro documentos espelha a ênfase colocada nesse tipo de turismo nos PENT: zero referências nos PNT e 33 referências no PENT e na sua revisão. De salientar que o facto de a expressão "turismo de natureza" não aparecer nos PNT poderá estar associada à circunstância de o produto 'turismo de natureza' só ter sido introduzido em Portugal, através da legislação, no final da década de 90 do século passado. As palavras "natureza" e "paisagem" são muito mais frequentes no PENT do que nos PNT (respetivamente 49 e 31 ocorrências no PENT contra 10 e 8 nos PNT), ilustrando a diferença entre as abordagens feitas ao turismo em áreas rurais. Pelo contrário, palavras como "rural", "rurais" ou "ruralidade" aparecem apenas 10 vezes nos documentos relativos ao PENT e à sua revisão, contra as 37 ocorrências nos PNT (15 no PNT 1985-1989 e 22 no PNT 1989-1993).

Com o objetivo de perceber a que temas se encontra associado, nos planos, o discurso sobre o espaço rural enquanto recurso turístico e sobre o turismo suscetível de ser realizado em áreas rurais, analisou-se o número de associações existente entre palavras/expressões relacionadas com o rural e palavras que representavam cada um dos temas. Na Tabela 2 encontram-se exemplos de palavras que representavam cada um dos temas.

Tabela 2. Palavras que representam os diversos temas e subtemas do discurso dos planos

\begin{tabular}{|c|c|c|}
\hline Temas & Subtemas & Palavras ou expressões que representam os subtemas (exemplos) \\
\hline \multirow{3}{*}{ Legislação e política } & Legislação & "Legislação", "regulamentação" e "lei". \\
\hline & Política e organização & "Classificação", "ordenamento" e "organiz". \\
\hline & Financiamento & "Financiamento", "financeir" e "fundo". \\
\hline Marketing & Marketing & "Promoção", "mercado" e "turista". \\
\hline \multirow{5}{*}{ Importância } & Desenvolvimento & "Desenvolvimento", "cresc" e "foment". \\
\hline & Conservação & “Conservação" e "preserv". \\
\hline & Valor & "Valor", "potencial" e "interesse". \\
\hline & Diversificação & "Diversific" e "novo". \\
\hline & Outros & "Benefício" e "qualidade de vida". \\
\hline \multirow{3}{*}{$\begin{array}{l}\text { Componentes do produto } \\
\text { turismo no espaço rural }\end{array}$} & População & "Popul", "habitante" e "comunidade". \\
\hline & Natureza & "Natur" e "protegida". \\
\hline & Agricultura & "Agric" e "agro". \\
\hline Turismo & Turismo & "Turismo" e "turístic". \\
\hline
\end{tabular}

Fonte: Elaboração própria. 
Tabela 3. Número de associações entre palavras/expressões relacionadas com "rural" e temas abordados nos PNT/PENT

\begin{tabular}{lcccccc}
\hline & $\begin{array}{c}\text { PNT } \\
(\mathbf{1 9 8 5 - 1 9 8 9 )}\end{array}$ & $\begin{array}{c}\text { PNT } \\
\text { (1989-1993) }\end{array}$ & $\begin{array}{c}\text { Total } \\
\text { PNTs }\end{array}$ & PENT & $\begin{array}{c}\text { Revisão } \\
\text { PENT }\end{array}$ & $\begin{array}{c}\text { Total PENT + } \\
\text { Revisão PENT }\end{array}$ \\
\hline Legislação e política & 9 & 17 & 26 & 0 & 4 & 4 \\
Marketing & 0 & 2 & 2 & 14 & 2 & 16 \\
Importância & 24 & 33 & 57 & 37 & 9 & 46 \\
Componentes do produto turismo no espaço rural & 12 & 16 & 28 & 7 & 2 & 9 \\
Turismo & 19 & 50 & 69 & 61 & 10 & 71 \\
\hline
\end{tabular}

Fonte: Elaboração própria.

Na Tabela 3 encontram-se os resultados relativos à análise destas associações. Pode observar-se, por exemplo, que nos PNT existem 69 associações entre o tema turismo e as três palavras/expressões relacionadas com o rural anteriormente identificadas.

O número de associações entre os temas e as palavras/expressões relacionadas com o rural é maior nos PNT do que nos PENT (PENT e respetiva revisão). É igualmente visível que este discurso com alguma associação ao rural versa, ao longo do período em análise, principalmente sobre o turismo e a importância de aspetos associados ao rural, incidindo também, por ordem decrescente de relevância sobre as componentes do produto turismo no espaço rural, sobre a legislação e política e, finalmente, sobre o marketing. Contudo, é importante realçar as diferenças existentes entre os diversos planos a este nível. Embora o tema do turismo seja muito abordado nos vários planos, nos PNT aparece mais associado ao rural propriamente dito, surgindo frequentemente nos PNT expressões como "turismo rural", "turismo no espaço rural", "TER" e expressões associadas a modalidades específicas de TER como "agroturismo".

Em contraste, nos PENT o turismo encontra-se mais associado à natureza, encontrando-se mais frequentemente expressões como "turismo de natureza", o que sugere que no período mais recente se começa a valorizar mais uma componente específica do turismo que se pode realizar em áreas rurais, em que há maior valorização e proximidade com a natureza. Neste contexto, nos PENT, as associações com o tema relativo à importância conferida a alguns aspetos do rural referem-se, também, sobretudo, à importância da natureza e do turismo de natureza:

“O Turismo na região Centro deverá crescer em número de turistas e em valor [...] A atracção de turistas estrangeiros será feita através dos produtos Touring e Turismo de Natureza" (PENT) (TURISMO DE PORTUGAL, 2007, p. 54).

A alusão às componentes mais identitárias do turismo em áreas rurais prevalece nos PNT. É muito interessante ainda verificar que, enquanto o tema da legislação e política assume maior relevância nos PNT do que nos PENT (com 26 e 4 associações com estes planos, respetivamente), o contrário acontece com o tema do marketing (com 2 associações nos PNT e 16 nos PENT). É importante referir que grande parte do texto onde há associações entre o discurso relacionado com o rural e o marketing, enfatiza, sobretudo, a importância da promoção do turismo de natureza junto dos turistas:

“Consolidação e desenvolvimento de 10 pro-
dutos turísticos estratégicos: Sol e Mar, Touring
Cultural e Paisagístico, City Break, Turismo de
Negócios, Turismo de Natureza [...] A inter-
venção nestes produtos envolve o desenvolvi-
mento de ofertas estruturadas, distintivas e ino-
vadoras [...] que nos permitam competir, com
êxito, nos mercados alvo" (PENT) (TURISMO
DE PORTUGAL, 2007, p. 6).

No sentido de analisar, no discurso especificamente associado ao rural, a importância rela- 
tiva que os vários temas abordados têm em cada plano, calculou-se, para cada plano, e para cada tema, a percentagem de associações existentes entre o prefixo "rura" e esse tema, relativamente ao número total de associações existentes entre o prefixo "rura" e todos os temas. Nos PNTs o discurso especificamente associado a rural está muito relacionado com o turismo e a importância do rural, registando-se, ao nível destas categorias de assuntos, $38 \%$ e $31 \%$ do total das associações existentes entre palavras com o prefixo "rura" e todas as categorias de assuntos consideradas na análise (Tabela 4). A seguir a estes assuntos, aqueles que assumem maior relevância são a "legislação e a política" e as "componentes do turismo no espaço rural", com 16\% e 15\% do total das associações, sendo o marketing um assunto muito pouco referenciado nestes planos (representando só 1\% das associações). Também no PENT e sua revisão, o discurso que se refere especificamente ao "rural" está grandemente associado à "importância do rural", onde existem $52 \%$ do total das associações com "rural" de cada plano.
Comparando os diversos planos, é possível perceber que a importância relativa da associação entre palavras com o prefixo "rura" e turismo é maior nos PNTs (onde também prevalecem expressões como "agroturismo", "TER" e "turismo rural"), enquanto a importância relativa da associação entre desenvolvimento e palavras com o prefixo "rura" é maior no PENT e sua revisão. Estes resultados sugerem que, nos PNTs, a perspetiva de o turismo no espaço rural constituir um importante instrumento de desenvolvimento do território é mais. Nos PENT existe uma preocupação com o facto de o turismo poder contribuir para o desenvolvimento das áreas rurais, não estando sempre tão patente como nos PNT que esse desenvolvimento se deva preconizar através do TER. Este facto pode ser observado quando na revisão do PENT se identificam as áreas em que se deve apoiar o investimento nas zonas com interesse para o turismo.

Quando se considera o discurso especificamente sobre o rural, nos PNT as associações entre este discurso e algumas componentes do produto

Tabela 4. Percentagem das associações entre palavras com o prefixo "rura" e temas abordados nos PNT/PENT relativamente ao número total de associações entre palavras com o prefixo "rura" e todos os temas considerados

\begin{tabular}{l|l|c|c|c|c|c|c}
\hline \multicolumn{2}{l|}{} & & & & & & \\
\end{tabular}

Fonte: Elaboração própria. 
'turismo no espaço rural', tais como a agricultura e a natureza, assumem maior relevância do que nos PENT. Encontram-se nos PNTs excertos como os seguintes:

"Portugal oferece boas possibilidades de desenvolvimento do turismo rural ou agroturismo que noutros países tem conhecido um grande êxito. A presença de vastos interiores ricos e atractivos naturais e paisagísticos, a originalidade da vida rural desconhecidas dos meios urbanos, a relação das pessoas com a natureza, a arquitectura das aldeias, são elementos que, correctamente organizados constituem um grande potencial turístico" (PNT 1985-1988) (SECRETARIA DE ESTADO DO TURISMO, 1985, p. 157).

“Fornecer condições especiais para o T.E.R. - Turismo em Espaço Rural - com a existência no interior do território de vastas áreas exuberantes e plenas de atracções naturais e paisagísticas de originalidade da vida rural, da arquitectura do interior e aldeã, do relacionamento dos habitantes com a natureza e do seu contacto afável com os visitantes" (PNT 1989-1992) (SECRETARIA DE ESTADO DO TURISMO, 1989, p. 121).

O contrário acontece com a associação entre este discurso e a população. No entanto, a alusão à população, nos PENT, aparece, sobretudo, no sentido de se garantir que a população das áreas rurais beneficie com o desenvolvimento do turismo:

"o desenvolvimento do setor [do turismo] deverá incidir em quatro vetores principais: - No desenvolvimento sustentável das regiões e comunidades locais, através do fomento ao empreendedorismo, desenvolvimento de fileiras relacionadas e potenciação da interação com as comunidades rurais e as suas atividades produtivas" (revisão do PENT) (TURISMO DE PORTUGAL, 2011, p. 31).

Embora não existam muitas associações entre o discurso especificamente sobre o rural e os temas do marketing e da legislação e política, o marketing e o subtema "política e organização" têm uma importância relativa maior nos PENT do que nos PNT e, em contraste, a legislação e financiamento assumem uma maior importância relativa nos PNT do que nos PENT. Esta mudança de perspetiva está patente nos seguintes excertos dos planos nacionais:

"Os meios para o fomento do turismo rural, no âmbito do Plano, são: [...] inventariação das propriedades e habitações que possam vir a ser integradas num programa de desenvolvimento futuro do turismo rural [...] criação de esquemas financeiros de apoio ao turismo rural a serem implementados pelas instituições de crédito vocacionadas para o crédito agrícola (PNT 1985-1988) (SECRETARIA DE ESTADO DO TURISMO, 1985, p. 216).

"Perante a nova legislação iniciou-se um processo que teve em vista a reclassificação das casas até aí inscritas [...] embora seja cada vez maior o conhecimento dos agentes locais e populações acerca do turismo no espaço rural, há ainda muito para fazer, especialmente em regiões do interior menos desenvolvidas" (PNT 1989-1992) (SECRETARIA DE ESTADO DO TURISMO, 1989, p. 187).

Estes resultados corroboram resultados de análises anteriores que revelam que o rural era, numa primeira fase do processo, associado a um produto estratégico - o TER - que era preciso regulamentar e fomentar através de financiamento para, numa segunda fase, com os PENT, passar a ser considerado como um produto que é preciso promover junto do mercado.

\section{Conclusão}

Neste trabalho procurámos averiguar o lugar do rural e da ruralidade nos planos nacionais de turismo entre 1985 e 2011. A principal conclusão da análise efetuada prende-se com a diminuição da relevância dada ao rural e aos produtos turísticos a ele associados, especialmente depois de 2007. Nestes planos, especialmente dos ante- 
riores a 2007, as referências ao rural têm sobretudo incidido sobre o fenómeno turístico e sobre a relevância que o rural assume no contexto do turismo. As referências a políticas mais específicas para promover o turismo no âmbito do rural são bastante mais escassas. Das análises efetuadas, constata-se também que o rural que surge nos PNT aparece frequentemente associado ao património natural e cultural, nomeadamente à agricultura, arquitetura típica, beleza paisagística e áreas protegidas. No que diz respeito aos produtos de turismo no espaço rural, por um lado, o PNT centra-se no turismo rural, agroturismo e turismo de habitação. Por outro lado, no PENT utiliza-se muito pouco a expressão turismo no espaço rural, incluindo uma referência mais indireta a práticas turísticas passíveis de serem realizadas no espaço rural, nomeadamente o touring cultural e paisagístico, o turismo de natureza, o turismo de saúde/bem-estar, o turismo gastronómico e o enoturismo.

Assim, observa-se que no PNT se enfatizam as características, os recursos e a necessidade do ordenamento dos territórios rurais como base para o desenvolvimento de produtos turísticos diversificados que sejam suscetíveis de competir com os tradicionais produtos de Sol e Mar. No PENT o rural e os produtos que nele podem desenvolver-se perdem a sua posição estratégica sendo, aparentemente, substituídos por uma maior ênfase no turismo de natureza e, consequentemente no papel das áreas protegidas nacionais para o seu desenvolvimento.

$\mathrm{Na}$ análise efetuada é, então, possível identificar duas grandes tendências correspondentes aos períodos a que se referem cada um dos planos analisados. A primeira relaciona-se com o que foi já referido, ou seja, a perda de relevância do rural enquanto produto turístico e a sua progressiva substituição pelo turismo de natureza que, no PENT, surge claramente como um dos dez produtos turísticos estratégicos de Portugal.

A segunda tendência relaciona-se com a passagem da ênfase colocada na regulamentação das atividades turísticas para o reconhecimento crescente da necessidade da sua promoção. Assim, nos anos oitenta do século $X X$, a preocupação com a regulamentação das diversas atividades/ modalidades turísticas em espaço rural era muito mais visível do que atualmente. A referência, nestes planos, à organização do turismo nas áreas rurais, à sua regulamentação e ao seu financiamento pode ser entendida à luz da recente consideração do TER como produto turístico, tendo-se verificado neste período, como já foi anteriormente referido, uma proliferação de legislação e de instrumentos financeiros. No entanto, durante muito tempo, grandes insuficiências continuaram a caracterizar o turismo (incluindo o TER) em Portugal, apesar dos avultados apoios comunitários no âmbito dos diversos Quadros Comunitários de Apoio (e.g. FIGUEIREDO, 2003).

Depois de 2007, é mais visível a preocupação com a melhoria e diversificação da oferta turística, estando mais patente uma preocupação com a promoção e o marketing dos produtos considerados estratégicos. No entanto, tanto ao nível do marketing, como em todo o PENT em termos gerais, a perspetiva sobre o rural deixou, como já mencionado, não só, de ser tão visível, como passou a ser menos abrangente, colocando quase toda a ênfase no contacto com a natureza e negligenciando a atenção dada a outros aspetos como o património cultural tangível e intangível das comunidades locais. Reconhecendo a importância que as áreas rurais possuem para o turismo, correspondendo a destinos multifacetados detentores de importante património natural e cultural preservado e autêntico, e reconhecendo também a relevância do turismo para a diminuição do isolamento das áreas rurais, bem como para a sua dinamização, seria importante que esta relevância fosse enfatizada nos planos e que se apontassem políticas e ações capazes de promover o desenvolvimento sustentável do turismo em áreas ruais.

Seria também importante, dado que o processo de regulamentação do TER se encontra agora mais estabilizado, que os planos nacionais de turismo pudessem neste momento fornecer linhas orientadoras para a promoção deste tipo de turismo. Considerando a importância que 
parece estar a ser conferida ao turismo de natureza, sugere-se também que nas eventuais políticas que possam vir a ser definidas para o TER, se enfatizem as oportunidades de proximidade com a natureza.

\section{Referências bibliográficas}

BUTLER, R. e HALL, M. Image and reimaging of rural areas. In: RICHARD, C., BUTLER, R., HALL, M. e JENKINS, J. (Eds.), Tourism and recreation in rural areas, Chichester: John Wiley \& Sons, 1998, p. 115-122.

CAVACO, C. O mundo rural português: desafios e futuros. In: CAVACO, C. (Coord.) Desenvolvimento Rural: Desafio e Utopia, Lisboa: CEG, 1999, p. 135-148.

C.C.E. The Future of Rural Society. Bulletin of the European Communities, 4/88, Bruxelas, 1988.

COVAS, A. Futuros do mundo rural português: De espaço produtos a espaço produzido: Mercados emergentes e neo-rurais. In: FIGUEIREDO, E., KASTENHOLZ, E., EUSÉBIO, M. C., GOMES, M. C., CARNEIRO, M. J., BATISTA, P. e VALENTE, S. (Coords.), O Rural Plural - Olhar o presente, imaginar o futuro. Castro Verde: $100 \mathrm{Luz}, 2011$, p. 59-70.

CUNHA, L. Economia e Política do Turismo. Lisboa, Porto: LIDEL, 2013.

FIGUEIREDO, E. Quantas mais 'aldeias típicas' conseguimos suportar? Algumas reflexões a propósito do turismo como instrumento de desenvolvimento local em meio rural. In: SIMÕES, O. e CRISTÓVÃO, A. (Eds.) Turismo em Espaços Rurais e Naturais, Coimbra: IPC, 2003, p. 65-81.

FIGUEIREDO, E. Um rural cheio de futuros? In: FIGUEIREDO, E., KASTENHOLZ, E., EUSÉBIO, M. C., GOMES; M. C., CARNEIRO, M. J., BATISTA, P. e VALENTE, S. (Coords.), O Rural Plural-Olhar o presente, imaginar o futuro. Castro Verde: 100 Luz, 2011, p. 13-46.

FIGUEIREDO, E. e RASCHI, A. Immersed in Green? Reconfiguring the Italian countryside through rural tourism promotional materials. In: HYDE, K., RYAN, C. e WOODSIDE, A. (Eds.) Field Guide for Case Study Research in Tourism, Hospitality and Leisure, Bingley: Emerald Group Publishing Limited, 2012, p. 17-44.

GARROD, B., WORNELL, R. e YOUELL, R. Re-conceptualising rural resources as countryside capital: The case of rural tourism. Journal of Rural Studies, Londres, 2006, n. 22, p. 117-128.
INE. Estatísticas do Turismo. Lisboa, INE, 2013.

JENKINS, J., HALL, C. M. e TROUGHTON, M. The reestructuring of rural economies: rural tourism and recreation as a government response. In: BUTLER, R. H., HALL, C. M. e JENKINS, J. M. (Ed.). Tourism and Recreation in Rural Areas, Chichester: John Wiley e Sons, 1998, p. 43-65.

KASTENHOLZ, E., DAVIS, D. e PAUL, G. Segmenting Tourism in Rural Areas: The Case of North and Central Portugal. Journal of Travel Research, Londres, v. 37, p. 353-363, 1999.

LANE, B. What is rural tourism? Journal of Sustainable Tourism, Londres, v. 2, n. 1/2, 7-21, 1994.

MATOS FERNANDES, A. The rurality reinvention discourse: urban demands, expectations and representations in the construction of an urban rurality project. In: SILVA, L. e FIGUEIREDO, E. (Eds.), Shaping Rural Areas in Europe - perceptions and outcomes on the present and the future, Dordrecht: Springer, 2013, p. 213-226.

PEIXOTO, P. Os Meios Rurais e a Descoberta do Património. Coimbra: Cadernos Oficina do Centro de Estudos Sociais, $\mathrm{n}$ 운 2002.

PÉREZ, X. P. Patrimonialização e transformação das identidades culturais. PORTELA, J. e CASTRO CALDAS, J. (Eds.), Portugal Chão. Oeiras: Celta Editora, 2003, p. 231-247.

PINA, P. Portugal: O turismo no século XX, Lisboa: Lucidus, 1988.

SECRETARIA DE ESTADO DO TURISMO. Plano Nacional de Turismo 1985-1988, Lisboa, SET, 1985.

SECRETARIA DE ESTADO DO TURISMO. Plano Nacional de Turismo 1989-1992, Lisboa, SET, 1989.

SILVA, S. e CARVALHO, P. Programas e Sistemas de Incentivos Europeus com Incidência na Actividade Turística em Espaço Rural: O Exemplo do PRIME (Portugal, 2000-2006). In: FIGUEIREDO, E., KASTENHOLZ, E., EUSÉBIO, M. C., GOMES, M. C., CARNEIRO, M. J., BATISTA, P. e VALENTE, S. (Coords.), O Rural Plural - Olhar o presente, imaginar o futuro. Castro Verde: 100 Luz, 2011, p. 315-328.

SOARES DA SILVA, D. e FIGUEIREDO, E. A Política do Rural na Política em Portugal - Quão novos são os novos desafios da estratégia Europa 2020 para o mundo rural?. Conferência Internacional Europa 2020/ II Conferência de Planeamento Regional e Urbano, 5-6 de Julho de 2013, Aveiro, Universidade de Aveiro. 
TURISMO DE PORTUGAL. Plano Estratégico Nacional do Turismo: Para o Desenvolvimento do Turismo em Portugal. Lisboa: Turismo de Portugal, ip. Disponível em: <http://www.turismodeportugal.pt/ Portugu\%C3\% AAs/turismodeportugal/publicacoes/ Documents/PENT\%202007.pdf $>$. Acedido no dia 12 de julho de 2013, 2013.

TURISMO DE PORTUGAL. Plano Estratégico Nacional do Turismo - Propostas para a revisão no horizonte
2015 - Versão 2.0. Lisboa: Turismo de Portugal, ip. Disponível em <http://www.turismodeportugal.pt/ Portugu\% C3\%AAs/turismodeportugal/Documents/ PENT_Revis\%C3\%A3o.pdf $>$. Acedido no dia 12 de julho de 2013, 2011.

ZHOU, Q. e DESANTIS, R. Usability issues in city tourism website design: a content analysis. In: 2005 IEEE International Professional Communication Conference Procedings, IEEE, 789-796, 2005. 